\title{
Thermal Stability of Beta Phase in a Cu-Al-Be Shape Memory Alloy
}

\author{
H. Flores Zúñiga, D. Rios-Jara, F.C. Lovey* and G. Guénin** \\ Instituto de Investigaciones en Materiales, U.N.A.M. A. Postal 70-360, 04510 Mexico \\ * Centro Atómico de Bariloche, 8400 S.C. de Bariloche, Argentina \\ ** Laboratoire GEMPPM-INSA de Lyon, ERA CNRS N³41, Bât. 502, 20 Albert Einstein, F-69621, \\ Villeurbanne cedex, France
}

\begin{abstract}
.
Thermal stability of the beta Cu-Al-Be phase with an eutectoid composition was studied by thermoelectric power measurements. Depending on the aging temperature, precipitates of the $\alpha_{2}$ and $\gamma_{2}$ phases were identified by optical and electron microscopies. From these results, C curves were deduced in a TTT diagram and a peritectic $\beta \rightarrow \alpha_{2}$ transition temperature was deduceed to be close to $275^{\circ} \mathrm{C}$.
\end{abstract}

\section{INTRODUCTION.}

In spite of the good shape memory behavior shown by $\mathrm{Cu}-\mathrm{Al}-\mathrm{Be}$ alloys $[1,2,3,4,5]$, not enough studies have bcen performed about the effect of $\mathrm{Be}$ in the low temperature region of the $\mathrm{Cu}-\mathrm{Al}$ phase diagram. In earlier work an $\mathrm{M}_{S}$ temperature dependence with composition was defined as $\mathrm{M}_{\mathrm{S}}=638-43 \% \mathrm{Al}-302 \% \mathrm{Be}(\mathrm{wt} . \%)$ [1,2]. Recently, Belkahla found an alternative $\mathbf{M}_{\mathrm{S}}$ relationship using a greater number of samples: $\mathrm{M}_{\mathrm{S}}=1245-71 \% \mathrm{Al}-893 \% \mathrm{Be}$ (wt.\%). Moreover, he found that $0,5 \mathrm{wt} \%$ $\mathrm{Be}$ addition decreases the eutectoid line in about $50^{\circ} \mathrm{C}$ in $\mathrm{Cu}-\mathrm{Al}$ alloys $[3,4]$.

We know that shape memory properties in Copper based alloys depend on the martensitic transformation stability, and therefore they also depend on the $\beta$ phase stability. This information is then important for applications. Some of the authors have reported a preliminary study on the $\beta$ phase stability made by calorimetric techniques [5]; a TTT diagram was deduced, but no information about the precipitates formed was presented. The aim of this work is to identify the precipitated phases during isothermal aging treatments, and to learn about the effect of Be additions in the low temperature region of the phase diagram. Thermo-electric power (TEP) measurements and transmission electron microscopy were used in order to obtain this information.

\section{EXPERIMENTAL.}

The alloy with chemical composition: $\mathrm{Cu}-11,5 \mathrm{wt} . \% \mathrm{Al}-0,5 \mathrm{wt} . \% \mathrm{Be}$ was provided by the Trefimétaux Society, as a $3 \mathrm{~mm}$. thickness plate ribbon. After quenching from about $650^{\circ} \mathrm{C}$ the measured $\mathrm{M}_{\mathrm{S}}$ temperature was between -45 and $-50^{\circ} \mathrm{C}$. 
A step quenching was applied to avoid $M_{S}$ variations caused by ordering [6]. The aging treatments were carried out in salt baths from $200^{\circ} \mathrm{C}$ to $500^{\circ} \mathrm{C}$ and in oil baths for lower temperatures. After each aging treatment, the samples were quenched to $100^{\circ} \mathrm{C}$ and left for 15 minutes at this temperature before performing TEP measurements at room temperature. TEP measurements were made on samples of $50 \times 3 \times 1 \mathrm{~mm}^{3}$, by applying a temperature gradient $(\Delta \mathrm{T})$ of $10^{\circ} \mathrm{C}$.

The microscopic observations were made in a Jeol 200-CX transmission electron microscope (TEM), and in an optical microscope. Disk shaped samples $(\phi=3 \mathrm{~mm})$ for TEM studies were cut by using a low speed diamond saw. Electrochemical thinning of the disks was performed by the twin jet method, until perforation of the samples. For electron microscopy, the chemical solution was: 25 vol\% $\mathrm{HPO}_{3}+25$ vol. $\% \mathrm{CH}_{3} \mathrm{OH}+\mathrm{H}_{2} \mathrm{O}$. The polishing solution used in optical microscopy was: $100 \mathrm{ml}$ of acetic acid (75\%aq.) $+20 \mathrm{ml}$ of $\mathrm{HNO}_{3}+30 \mathrm{ml}$ of acetone; another etching solution was $95 \mathrm{ml}$ of ethanol $+2 \mathrm{gr}$ of $\mathrm{FeCl}_{3}+2 \mathrm{ml}$ of $\mathrm{HCl}$.

\section{RESULTS.}

\subsection{Thermoelectric power measurements.}

Figure 1 shows the thermoelectric power (TEP) evolution with time for agings at several temperatures. Two different stages can be clearly identified: The former is an increase of the TEP values, and the second corresponds to a decrease of the same. The first stage does not correspond to any change detected by calorimetric measurements. In contrast, the second stage occurs at times when clear variations in the calorimetric response are detected due to precipitation.

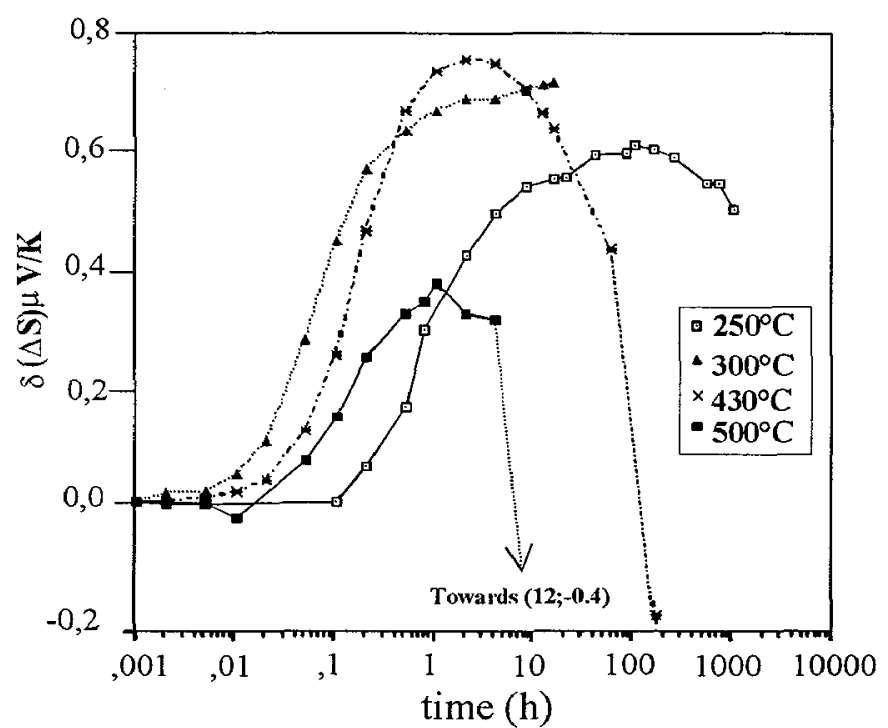

Figure 1 : Thermoelectric power during aging.

\subsection{Transmission Electron Microscope Observations.}

TEM observations showed two different types of precipitates, immersed in the $\beta$ phase matrix with a well defined $\mathrm{DO}_{3}$ ordered structure, as reported before [4]. The first type of precipitates appeared after aging at low temperatures, between $200^{\circ} \mathrm{C}$ and $275^{\circ} \mathrm{C}$, and they were plate shaped with edges parallel to the cubic $\{100\}$ planes of the $\beta$ phase. The cristallographic analysis of these precipitates shows a structure similar to taht of the $\alpha_{2}$ phase of $\mathrm{Cu}-\mathrm{Al}$ alloy $[7,8]$.

For aging at higher temperatures, from 300 to $350^{\circ} \mathrm{C}$, the

precipitates have a polyhedral shape, these preci-pitates are very similar to the $\gamma_{2}$ precipitates found in $\mathrm{Cu}-\mathrm{Al}-\mathrm{Ni}$ alloys $[9,10]$, and also similar to the $\gamma_{2}$ precipitates in Cu-Zn-Al alloys[11]. These precipitates were identified as a $\gamma_{2}$ phase. 


\section{DISCUSSION.}

The TEP results shows that for low temperatures, the first evolution stage has an activation energy of $E_{A}=0,63 \pm 0,03 \mathrm{eV}$. It is interesting to note that a comparable energy value was reported by Van Humbeeck for vacancies diffusion in $\beta \mathrm{Cu}-\mathrm{Zn}-\mathrm{Al}$ alloys, measured by positron annihilation [12]. The first stage could then be attributed to a diffusion mechanism of quenching vacancies in the $\beta$ phase. On the other hand, the activation energy for ordering has been reported as $0,3 \pm 0,05 \mathrm{eV}[6]$, it is therefore possible that an ordering process occurs during vacancy migration.

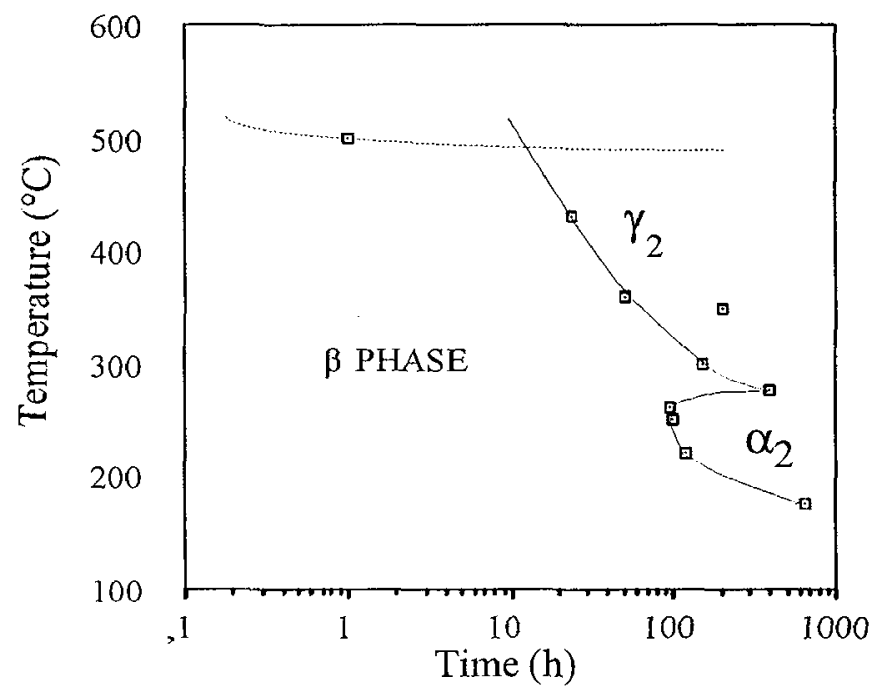

Figure 2. TTT diagram.

From our results we can construct a TTT diagram as shown in figure 2. C curves in this diagram correspond to the formation of the equilibrium phases. For the low temperature domain (from 175 to $275^{\circ} \mathrm{C}$ ) the proposed reaction is $\beta \rightarrow \alpha_{2}+\beta$. In the middle domain (from $275^{\circ} \mathrm{C}$ to $350^{\circ} \mathrm{C}$ ) the precipitation is proposed to be $\beta \rightarrow \gamma_{2}+\alpha$. For the higher temperature region (higher than $500^{\circ} \mathrm{C}$ ) the reaction $\beta$ $\rightarrow \alpha+\beta+\gamma_{2}$ has been proposed by Belkahla et a1. [3].

Close to the stoichiometric composition $\left(\mathrm{Cu}_{3} \mathrm{Al}\right)$ of the equilibrium phase diagram, Belkahla et al. reported that $\mathrm{Be}$ adjunction produces a general decrease in temperature of the characteristic transformations, with no shifts in composition. Therefore, the $\mathrm{Cu}-\mathrm{Al}$ Be phase diagram could be deduced from the $\mathrm{Cu}-\mathrm{Al}$ one by a simple displacement toward the lower temperatures. The eutectoid temperature is decreased in about $50^{\circ} \mathrm{C}$ (i.e., to $500^{\circ} \mathrm{C}$ ). The peritectoid temperature could be lowered too in about $50^{\circ} \mathrm{C}$, which locates this temperature close to $300^{\circ} \mathrm{C}$.

From the results presented here, the peritectoid temperature can be located more precisely at $275^{\circ} \mathrm{C}$, because the $\alpha_{2}$ phase was identified under this temperature.

This diagram is helpful to know the stability of the $\beta$ phase, and in consequence that of the martensitic transformation and the one way shape memory applications. However, when the important transformation characteristic is the hysteresis, a more limited stability domain must be taken into account.

\section{CONCLUSIONS.}

The main conclusions of this work are:

1. The Thermoelectric power results show a strong evolution before precipitation, this process was attributed to a vacancy diffusion with an activation energy of $0,63 \pm 0,03 \mathrm{eV}$. The $\mathrm{DO}_{3}$ ordering occurs probably during vacancy diffusion. 
2. Two types of precipitation were identified in $\beta \mathrm{Cu}-\mathrm{Al}-\mathrm{Be}$ for agings at low temperatures, below $275^{\circ} \mathrm{C}$ the precipitates were of $\alpha_{2}$ phase, and for higher temperatures the $\gamma_{2}$ phase was found.

3. The equilibrium phase diagram reported by Belkahla can be improved by adding a peritectoid reaction close to $275^{\circ} \mathrm{C}$.

\section{Acknowledgments:}

H. Flores Zúniga acknowledges the Tréfimétaux society for the alloy provided, and the GEMPPM INSA de Lyon,FRA.

\section{REFERENCES}

1 A. Higuchi, K. Suzuki, Y. Matsumoto, K. Sugimoto, S. Komatsu, N. Nakamura. Proc. Int. Conf. on Martensitic Transformation, Leuven, pp. 767 (1982).

2 A. Higuchi, K. Suzuki, K. Sugimoto, N. Nakamura, I.C.O.M.A.T. 86, Trans. Jap. Inst. Met., Japan, 886 (1986).

3 S. Belkahla, G. Guénin, J. de physique IV.C-4, FRA, 145 (1991).

4 S. Belkahla, H. Flores Zúñiga, G. Guénin, Mat. Sci. \& Eng. A 169, 119 (1993).

5 H. Flores Zúñiga, S. Belkahla, G. Guénin. J. de Physique IV. C-4, FRA, 289 (1991).

6 A. Planes. J.L. Macqueron, M. Morin, G.Guénin. Mat. Sci. \& Eng, 50, 53 (1981).

7 N. Kuwano, T. Doi, T.Eguchi. Trans. Jap. Inst. Met., 18, 807 (1977).

8 N. Kuwano, T. Doi, T. Eguchi. Trans. Jap. Inst. Met., 21,359 (1980).

9 P. Fisher, D. Dunne, N. Kennon. Proc. of the Int. Conf. On Martensitic Transformation. Nara, Japan, Trans. Jap. Inst. Met., 946 (1986).

10 M.A. Dvorack, N. Kuwano, S. Polat, H. Chen, C.M. Wayman. Scripta Metall., 17, 1333 (1983).

11 F.C. Lovey, E. Cesari, C. Auguet, Ll. Mañosa, R. Rapacioli. Proc. of the Int. Conf. On Martensitic Transformation: Materials Science Forum, Vol. 56, 493 (1990).

12 J. Van Humbeeck, D. Segers, L. Delaey. Scripta Metall., 19,477 (1985). 